\title{
新时代背景下《调研统计与预测》 课程激励机制研究
}

张今欣

湖南国防工业职业技术学院

DOI:10.32629/er.v2i12.2246

[摘要] 《调研统计与预测》是高职营销类专业的一门职业核心能力课,专业性和操作性较强,使学生在完成工作任务过程中学会市场调查与 预测的相关知识和技能,培养学生的实际操作能力,但是学生在互联网时代背景下,自律性较差,自控能力较弱,教师稍有疏忽,机房学习往往成了 游戏竞技场地; 学生小组合作式容易浑水摸鱼,难以做到个人全方位、全过程考核; 学生文字撰写能力较弱,学生容易网上抄袭; 因此,能够全 方位、全过程、全员监控的考核方案尤为重要。

[关键词] 新时代; 调研统计与预测；课程考核

学生考核是课程管理工作的重要组成部分, 考核方案的完善与否, 直 接决定课程的教学效果。高职生是一个相对特殊的学习群体.生源素质参 差不齐, 学生来源于初、高中及社会青年中, 他们的知识层次参差不齐, 家 庭背景差别各异。在互联网时代背景下, 男生沉溺于网络游戏, 女生迷恋追 剧, 已成普遍。高职学生厌学心理严重, 部分基础差的学生入学后听不懂课, 又缺乏刻苦学习的毅力。传统的考核方式已很难适应新形势的需要, 必须 不断对考核观念和考核体制的探索与创新。本文从新时代背景下高职职学 生的学情入手, 提出了在新时代背景下对中职学生的考核方法。

\section{1 课程概述}

《调研统计与预测》课程是营销类专业的专业课程, 高职院校开设该 课程注重培养学生的市场调查与预测综合技能, 能参与完成公司调研项目, 胜任公司调研部门岗位。本课程要求学生掌握各种市场调查实践中常用的 组织调查的方式、搜集资料方法以及各种常用的定性市场预测法、定量市 场预测法并能撰写汽车市场调查报告。通过本课程的学习, 使学员掌握汽 车市场调查与预测的基本知识、基本原理, 能够正确地运用所学的调查和 预测方法解决市场活动中的实际问题, 具备良好的实际应用能力, 培养具 有汽车市场调查与预测的综合技能的市场调研人员及基层营销管理人员。

\section{2 新时代背景下《调研统计与预测》的学情现状及原因分析}

2.1学生自控能力差

高职学生基本都是 00 后的孩子, 是手机时代的原住民, 在校一年多的 学习中已经习惯了信息化教学, 对网络数字资源平台使用非常熟练。但是 高职院校的学生学习自控能力差, 容易迷恋网络游戏、网络电视等, 因此利 用多种方式多种手段, 加强监管措施, 迫在眉睫。

\section{2文字表达能力欠缺}

在互联网普及的背景下, 00 后的学生虽然经常通过文字交流, 但是仅 限于口语化、简短的日常交流, 学生的书面表达能力欠缺, 缺乏系统性和完 整性, 大部分教师采用模版教学, 学生只需稍加改动, 即可完成任务, 但是 学生缺乏自己的思想和独立操作的调研技能, 创新能力极为欠缺, 因此激 励式考核方案显得尤为重要。

2.3 存在 “浑水摸鱼”、“搭便车” 现象

目前大部分课程采用小组合作式教学, 学生团队完成任务, 该班一部 分学生在团队合作中存在 “浑水摸鱼”、“搭便车” 的现象, 且数字化的方 案容易被复制粘贴, 抄袭事件屡有发生, 自己不动手却享受团队的成果, 为 了保证人人动手, 人人参与, 即使有明确分工, 但是教师对团队各成员的参 与及完成情况, 难以考量。

\section{3 《调研统计与预测》课程考核方案对策建议}

3.1以团队考核的形式进行全员考核
对于学生自控力差、浑水摸鱼且文字表达能力欠缺等学情, 教师采用 多种教学方法与手段的同时, 全方位、全过程的考核尤为重要,而考核的主 要难度就是学生数量多, 教师难以准确把控, 因此以小组成立部门, 以部门 对各成员进行考核。

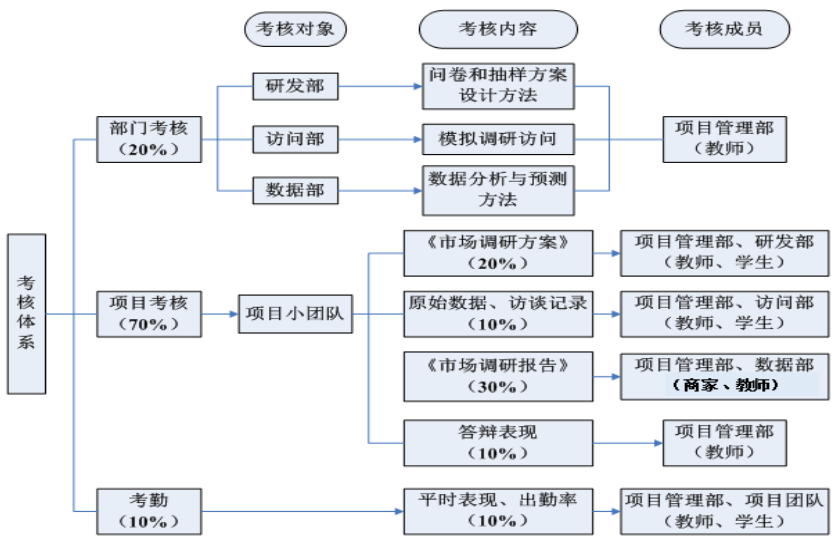

图1 新时代背景下《调研统计与预测》课程考核体系

除了各部门对每位学生考核外, 针对学生没有把电脑、手机用在学习 上, 可以在时间上给予限制, 而且对分工情况进行不定时随机抽查, 如某同 学负责答案设计, 我会在课堂抽查提问, 某一题的答案是怎样设计的, 如有 团队包庇, 则取消该团队所有成员此模块的成绩, 加大惩罚力度, 强调诚信 为人的重要性; 且针对个人与团队都设计考核方案, 考核综合自评、互评 等多元评价, 保证每人参与、每人考核通过。

表1 考核方式与考核标准

\begin{tabular}{|c|c|c|c|c|c|c|}
\hline \multirow{2}{*}{ 项目编号 } & \multirow{2}{*}{$\begin{array}{l}\text { 考核点及 } \\
\text { 占项分 } \\
\text { 值比 }\end{array}$} & \multirow{2}{*}{$\begin{array}{l}\text { 建议考核 } \\
\text { 方式 }\end{array}$} & \multicolumn{3}{|c|}{ 评价标准 } & \multirow{2}{*}{$\begin{array}{l}\text { 成绩比例 } \\
(\%)\end{array}$} \\
\hline & & & 优 & 良 & 及格 & \\
\hline \multirow[t]{2}{*}{ P5-1 } & $\begin{array}{l}\text { 1. 市场调 } \\
\text { 查方案 } \\
(80 \%)\end{array}$ & 成果考核 & $\begin{array}{l}\text { 项目方案 } \\
\text { 设计合理, } \\
\text { 可实施; ; } \\
\text { 案内容完 } \\
\text { 整。 }\end{array}$ & $\begin{array}{l}\text { 项目方案 } \\
\text { 设计基本 } \\
\text { 合理, 可实 } \\
\text { 施; 方案内 } \\
\text { 察。 } \\
\text { 基本完 } \\
\end{array}$ & $\begin{array}{l}\text { 项目方案 } \\
\text { 设计基本 } \\
\text { 可实施; 方 } \\
\text { 案内容 } \\
\text { 明显缺陷。 }\end{array}$ & \multirow[t]{2}{*}{$15 \%$} \\
\hline & $\begin{array}{c}\text { 2. 项目公 } \\
\text { 共考核点 } \\
(20 \%)\end{array}$ & \multicolumn{4}{|c|}{ 见表 2} & \\
\hline \multirow[t]{2}{*}{ P5-2 } & $\begin{array}{l}\text { 1、问卷设 } \\
\text { 计 }\end{array}$ & 成果考核 & $\begin{array}{l}\text { 问卷设计 } \\
\text { 合理, 可实 } \\
\text { 施; 内容 } \\
\text { 整, 符合要 } \\
\text { 求。 }\end{array}$ & $\begin{array}{l}\text { 问卷设计 } \\
\text { 基本合理, } \\
\text { 可实施; 内 } \\
\text { 容基本符 } \\
\text { 合要求。 }\end{array}$ & $\begin{array}{l}\text { 问巻设计 } \\
\text { 基本宪 } \\
\text { 施; 内完 } \\
\text { 明显缺陷。 }\end{array}$ & \multirow[t]{2}{*}{$15 \%$} \\
\hline & 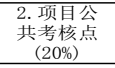 & \multicolumn{4}{|c|}{ 见表 2} & \\
\hline \multirow{3}{*}{ P5-3 } & $\begin{array}{l}\text { 1. 原始数 } \\
\text { 据 }(50 \%)\end{array}$ & 成果考核 & $\begin{array}{l}\text { 数据真实、 } \\
\text { 整。 }\end{array}$ & $\begin{array}{l}\text { 数据完整, } \\
\text { 无明丵错 } \\
\text { 误。 }\end{array}$ & $\begin{array}{l}\text { 数据完整, } \\
\text { 无重大错 } \\
\text { 误。 }\end{array}$ & \multirow{3}{*}{$10 \%$} \\
\hline & $\begin{array}{l}\text { 2. 访谈记 } \\
\text { 录 }(30 \%)\end{array}$ & 成果考核 & $\begin{array}{l}\text { 访谈记录 } \\
\text { 真细。 }\end{array}$ & $\begin{array}{l}\text { 访谈记录 } \\
\text { 基本合理。 }\end{array}$ & $\begin{array}{l}\text { 有访谈记 } \\
\text { 录。 }\end{array}$ & \\
\hline & $\begin{array}{c}\text { 3. 项目公 } \\
\text { 共考核点 } \\
(20 \%)\end{array}$ & \multicolumn{4}{|c|}{ 见表 2} & \\
\hline
\end{tabular}




\begin{tabular}{|c|c|c|c|c|c|c|}
\hline \multirow{2}{*}{ 项目编号 } & \multirow{2}{*}{$\begin{array}{l}\text { 考核点及 } \\
\text { 占项目分 } \\
\text { 值比 }\end{array}$} & \multirow{2}{*}{$\begin{array}{c}\text { 建议考核 } \\
\text { 方式 }\end{array}$} & \multicolumn{3}{|c|}{ 评价标准 } & \multirow{2}{*}{$\begin{array}{c}\text { 成嘖比例 } \\
(\%)\end{array}$} \\
\hline & & & 优 & 良 & 及格 & \\
\hline \multirow{4}{*}{ P5-4 } & $\begin{array}{l}\text { 1. 数据录 } \\
\text { 入(20\%) }\end{array}$ & 操作考核 & $\begin{array}{l}\text { 问 卷数 据 } \\
\text { 录入方法 } \\
\text { 正确, 熟练 } \\
\text { 操作。 }\end{array}$ & $\begin{array}{l}\text { 问 卷数据 } \\
\text { 录入方法 } \\
\text { 正确, 会操 } \\
\text { 作。 } \\
\end{array}$ & $\begin{array}{l}\text { 问卷数据 } \\
\text { 录入操 作 } \\
\text { 无明显错 } \\
\text { 误。 }\end{array}$ & \multirow{4}{*}{$20 \%$} \\
\hline & $\begin{array}{l}\text { 2. 数据分 } \\
\text { 析 }(30 \%)\end{array}$ & 操作考核 & $\begin{array}{l}\text { 数据分析 } \\
\text { 方法很好 } \\
\text { 掌握, 熟练 } \\
\text { 操作。 }\end{array}$ & $\begin{array}{l}\text { 数据分析 } \\
\text { 方法较好 } \\
\text { 掌握, 基本 } \\
\text { 会操作。 }\end{array}$ & $\begin{array}{l}\text { 数据分析 } \\
\text { 方法基本 } \\
\text { 掌握, 操作 } \\
\text { 无明显错 } \\
\text { 误。 }\end{array}$ & \\
\hline & $\begin{array}{l}\text { 3. 市场预 } \\
\text { 测 (30\%) }\end{array}$ & 方法考核 & $\begin{array}{l}\text { 市场预 测 } \\
\text { 方法很好 } \\
\text { 掌握。 }\end{array}$ & $\begin{array}{l}\text { 市场预测 } \\
\text { 方法较好 } \\
\text { 掌握。 }\end{array}$ & $\begin{array}{l}\text { 市场预 测 } \\
\text { 方法基本 } \\
\text { 掌握。 }\end{array}$ & \\
\hline & $\begin{array}{c}\text { 4. 项目公 } \\
\text { 共考核点 } \\
(20 \%)\end{array}$ & \multicolumn{4}{|c|}{ 见表 2} & \\
\hline \multirow[t]{2}{*}{ P5-5 } & $\begin{array}{c}\text { 1. 市场调 } \\
\text { 研报告 } \\
(80 \%)\end{array}$ & 成果考核 & $\begin{array}{l}\text { 调 研报告 } \\
\text { 内容整, } \\
\text { 思路清晰, } \\
\text { 符合要求; } \\
\text { 分析到位, } \\
\text { 结论可靠, } \\
\text { 建议合理 } \\
\text { 可行。 }\end{array}$ & $\begin{array}{l}\text { 调 研报 告 } \\
\text { 内容完整, } \\
\text { 基本符合 } \\
\text { 要求; 分 } \\
\text { 析、结论、 } \\
\text { 建议较为 } \\
\text { 合理。 }\end{array}$ & $\begin{array}{l}\text { 调研报告 } \\
\text { 内容完整, } \\
\text { 基本符合 } \\
\text { 要求; 图表 } \\
\text { 分析无明 } \\
\text { 显错误。 }\end{array}$ & \multirow[t]{2}{*}{$30 \%$} \\
\hline & $\begin{array}{c}\text { 2. 项目公 } \\
\text { 共考核点 } \\
(20 \%)\end{array}$ & \multicolumn{4}{|c|}{ 见表 2} & \\
\hline \multirow[t]{2}{*}{ P5-6 } & $\begin{array}{l}\text { 1. 项目答 } \\
\text { 辩 }(80 \%)\end{array}$ & 答辩 & $\begin{array}{l}\text { 熟悉项 目 } \\
\text { 内容和工 } \\
\text { 作流程; 很 } \\
\text { 好答辩。 }\end{array}$ & $\begin{array}{l}\text { 知 道项 目 } \\
\text { 内容和工 } \\
\text { 作流程; 较 } \\
\text { 好答辩。 }\end{array}$ & $\begin{array}{l}\text { 参 与 项 目 } \\
\text { 工作流程; } \\
\text { 完成答辩。 }\end{array}$ & \multirow[t]{2}{*}{$10 \%$} \\
\hline & $\begin{array}{c}\text { 2. 项目公 } \\
\text { 共考核点 } \\
(20 \%)\end{array}$ & \multicolumn{4}{|c|}{ 见表 2} & \\
\hline & & & & & & 100 \\
\hline
\end{tabular}

3. 2 以过程考核的形式进行全过程考核

为全面考核学生的学习情况, 本课程主要以过程考核为主, 考核涵盖 项目任务全过程, 主要从设计市场调研方案到撰写市场调研报告, 最后项 目答辩等五个方面来进行考核。

表2 项目公共考核评价标准

\begin{tabular}{|c|c|c|c|c|}
\hline \multirow{2}{*}{ 项目公共考核点 } & \multirow{2}{*}{ 建议考核方式 } & \multicolumn{3}{|c|}{ 评价标准 } \\
\hline & & 优 & 良 & 及格 \\
\hline $\begin{array}{l}\text { 1. 职业道德 } \\
(30 \%)\end{array}$ & $\begin{array}{c}\text { 教师评价+自评+ } \\
\text { 互评 }\end{array}$ & $\begin{array}{c}\text { 诚实严谨, 具有 } \\
\text { 实事求是的职业 } \\
\text { 道德, 不违背职 } \\
\text { 业道德与营销伦 } \\
\text { 理。 }\end{array}$ & $\begin{array}{c}\text { 诚实严谨, 职业 } \\
\text { 道德较好。 }\end{array}$ & $\begin{array}{c}\text { 没出现违纪、违 } \\
\text { 规现象。 }\end{array}$ \\
\hline $\begin{array}{l}\text { 2. 学习态度 } \\
(30 \%)\end{array}$ & 教师评价 & $\begin{array}{c}\text { 学习积极性高, } \\
\text { 虚心好学。 }\end{array}$ & $\begin{array}{c}\text { 学习积极性较 } \\
\text { 高。 }\end{array}$ & 没有厌学现象。 \\
\hline $\begin{array}{l}\text { 3. 团队合作精神 } \\
(20 \%)\end{array}$ & 互评 & $\begin{array}{c}\text { 具有良好的团队 } \\
\text { 合作精神, 热心 } \\
\text { 帮助团队其他成 } \\
\text { 员。 }\end{array}$ & $\begin{array}{c}\text { 具有较好的团队 } \\
\text { 合作精神, 能帮 } \\
\text { 助团队其他成 } \\
\text { 员。 }\end{array}$ & $\begin{array}{c}\text { 能与团队完成项 } \\
\text { 目任务。 }\end{array}$ \\
\hline $\begin{array}{c}\text { 4. 交流及表达能 } \\
\text { 力 (10\%) }\end{array}$ & 互评+教师评价 & $\begin{array}{l}\text { 能用专业语言正 } \\
\text { 确、流利地展 } \\
\text { 项目成果。 }\end{array}$ & $\begin{array}{l}\text { 能用专业语言正 } \\
\text { 确、较为流利地 } \\
\text { 阐述项目。 }\end{array}$ & $\begin{array}{l}\text { 能用专业语言基 } \\
\text { 本正确地阐述项 } \\
\text { 目,无重大失误。 }\end{array}$ \\
\hline $\begin{array}{c}\text { 5. 组织协调能力 } \\
(10 \%)\end{array}$ & 互评+教师评价 & $\begin{array}{l}\text { 能根据工作任 } \\
\text { 务, 正确控制、激研和调小组活 } \\
\text { 动过程。 }\end{array}$ & $\begin{array}{l}\text { 能根据工作任 } \\
\text { 务, 较正确控制、 } \\
\text { 激版和协调小组 } \\
\text { 活动过程。 }\end{array}$ & $\begin{array}{l}\text { 能根据工作任 } \\
\text { 务, 控制、激励和 } \\
\text { 协调小组活动过 } \\
\text { 程, 无重大失误。 }\end{array}$ \\
\hline
\end{tabular}

3. 3在课程思政背景下加大公共项目考核比重

在以培养技能为主的高职, 思政育人也尤为重要, 针对学生的职业道 德、学习态度、团队合作精神以及交流与表达能力等方面的考核也须系统 化, 项目化。

3.4 分层考核

各学生组成的团队根据上学期的期末成绩平均分进行分层, 自行根 据教师要求设定难度较大或者难度较低的阶段目标和最后总目标, 教师 根据团队是否完成预期目标进行检验考核, 且就实际完成情况进行排名 与奖励。

3.5 定期排名、公示

将各个环节设计考核标准, 每个小阶段定期统计成绩, 公示结果排名, 及时起到监督激励作用, 考核标准、考核过程与考核结果做到公开透明, 让学生对团队的得分与排名情况做到心中有数, 及时地了解自己对团队的 贡献度。

考核主要以正面激励为主, 对于表现优秀、排名靠前的团队实行物质 和精神奖励, 物质奖励的资金来源于各团队的盈利收入。对于排名较落后 的公司团队象征性惩罚, 如搞卫生, 表演小节目等。合理的竞争和奖惩机制 是保证教学效果必不可少的重要机制!

构建一套针对学生不同层次的全过程、全方位的考核方案。学生组建 团队, 根据学生的不同层次, 设计不同等级的团队考核方案, 为了防止浑水 摸鱼, 针对各团队定期抽查; 教师定期考核, 从每次课、每个工作阶段以及 期末三个层次进行考核, 监督激励尽量及时, 实现考核全过程化; 针对学生 的参与过程、阶段结果进行过程与结果双重考核, 全方位考核; 在课程思 政的背景下, 将加大职业道德、诚信为人等考核比重。

\section{[参考文献]}

[1]刘丹. 以工作过程为基础的高职院校市场营销专业课程改革探究 [J]. 商业经济,2018(02):184-185.

[2]于相贤. 基于工作过程的市场调查实践课教学设计改革与实施一 一以河套学院为例 [J].教育教学论坛,2019(44):140-142.

[3] 韩二东.大数据时代背景下市场调查与预测课程教学模式改革研 究[J].高教学刊,2019(17):138-140.

[4]赵志红.《市场调研实务》课程理实一体化教学改革实践与思考 [J]. 企业与管理,2019(07):76-77.

[5]李顽.过程性考核在高职艺术设计课程中的实践研究 [J].大众文 艺,2019(20):246-247.

\section{作者简介：}

张今欣 (1987--), 女, 汉族, 湖南娄底新化人, 讲师兼中级经济师, 硕 士研究生,主攻市场营销、市场调研、创新创业方向。 